\title{
Howard Temin Award
}

National Cancer Institute

\section{Source}

National Cancer Institute. Howard Temin Award. NCI Thesaurus. Code C19269.

The goal of the National Cancer Institute's ( $\mathrm{NCl}$ ) Howard Temin Award is to bridge the transition from a mentored research environment to a National Cancer Institute independent research career for scientists who have demonstrated unusually high potential during their initial stages of training and development. This special award is aimed at fostering the research careers of outstanding, junior, basic, clinical, and behavioral scientists who are committed to developing research programs highly relevant to the understanding of human biology and human disease as it relates to the etiology, pathogenesis, prevention, diagnosis, and treatment of cancer. 